\title{
Unexpected Aldehyde Generation in the Exhaust Gas at Waste Incineration Facilities
}

\author{
Xue ChU, ${ }^{* 1, * 2}$ Yasuro FuSE, ${ }^{* 1, * 3 \dagger}$ Takato SASAKI, ${ }^{* 1}$ Ichiro AIZawa, ${ }^{* 4}$ Masahiro OGUCHI, ${ }^{* 5}$ and \\ Yuichi MIYAKE*6
}

*1 Graduate School of Science and Technology, Kyoto Institute of Technology, Matsugasaki, Gosyokaidocho, Sakyo, Kyoto 606-8585, Japan

*2 Shimadzu Corporation, 1 Kuwabara-cho, Nishinokyo, Nakagyo, Kyoto 604-8511, Japan

*3 Center for Environmental Science, Kyoto Institute of Technology, Matsugasaki, Gosyokaidocho, Sakyo, Kyoto 606-8585, Japan

*4 IZAK Co. Ltd., 1181 Daikaijino-cho, Uozu, Toyama 937-0816, Japan

*5 Center for Material Cycles and Waste Management Research, National Institute for Environmental Studies, Tsukuba, Ibaraki 305-8506, Japan

*6 Graduate Division of Nutritional and Environmental Science, University of Shizuoka, Shizuoka 422-8526, Japan

\begin{abstract}
Acid gases generated during the thermal treatment of waste are neutralized using devices, such as bag filters coated with slaked lime. However, residual trace organic substances can react with the highly reactive slaked lime. This study investigates the dynamics of organic substances generated in the bag filter when slaked lime is used in the exhaust gas treatment process. The mechanism of aldehyde generation was clarified using head space gas chromatography mass spectrometer (HS-GC/MS). Results indicated that methanol was converted to formaldehyde at a conversion ratio of $0.097 \%$ and ethanol was converted to acetaldehyde at a conversion ratio of $0.260 \%$. In addition, when amines used as emulsifiers during slaked lime production persisted in the matrix, acetaldehyde formed at a maximum concentration of $121 \mathrm{mg} / \mathrm{m}^{3}$. The simulation method developed in this study can be used for the initial evaluation of aldehydes unexpectedly produced in an incineration treatment facility.
\end{abstract}

Keywords Headspace-GC/MS, aldehydes, highly reactive lime, industrial waste incineration treatment facility, atmospheric pollution

(Received June 25, 2019; Accepted August 8, 2019; Advance Publication Released Online by J-STAGE August 16, 2019)

\section{Introduction}

The Japanese waste incineration treatment system mainly consists of three parts: a combustion chamber, a cooling system, and an exhaust gas treatment system. The waste quantitative supply device continuously inputs waste in quantitative quantities. It burns at $800^{\circ} \mathrm{C}$ for $2 \mathrm{~s}$ or more in the combustion chamber. At the time of combustion, air is supplied to rapidly raise the furnace temperature, and at the time of shutdown, the furnace temperature is kept high and the waste is burned out. Thereafter, the temperature is cooled to $200^{\circ} \mathrm{C}$ or less by a cooling facility, a part of the accumulated dust is removed, and it passes through an exhaust gas treatment facility, such as a bag filter. The acid gas is neutralized in the bag filter, which is coated with highly reactive slaked lime before being released into the atmospheric environment. ${ }^{1}$ However, the presence of organic substances in the exhaust gas, which should have easily decomposed at $800^{\circ} \mathrm{C}$, has not been extensively investigated since the enactment of the Act on Special Measures against

† To whom correspondence should be addressed.

E-mail: fuse@environ.kit.ac.jp
Dioxins. And, after burning at $800^{\circ} \mathrm{C}$, it is also reported that dioxins are also produced in subsequent processes, such as an electronic dust collector. $^{2}$ Details on chemical substances emitted from industrial waste incineration facilities were not easily available until Oguchi conducted detailed analyses of incineration residues and exhaust gas samples from industrial waste incineration facilities and identified the chemical substances actually emitted. ${ }^{3}$ His study measured levels of VOCs, such as 1,4-dioxane and aldehydes, which are target substances in the Pollutant Release and Transfer Register (PRTR). Further, the study indicated that the actual discharge from incineration facilities differed depending on the type of facility, such as the main treated waste categories or exhaust gas treatment system. There are many chemical reactions in the process of waste incineration. ${ }^{4-6}$ In order to control the concentration of toxic chemicals in the final exhaust gas, ${ }^{7,8}$ it is very important to understand the possible chemical reactions in each process.

In our previous studies, we clarified that 1,4-dioxane was generated by intramolecular dehydration cyclization and bimolecular dehydration cyclization of residual surface emulsifiers (such as diethylene glycol and ethylene glycol) of highly reactive slaked lime used in dry neutralizer bag filters. ${ }^{9,10}$ 


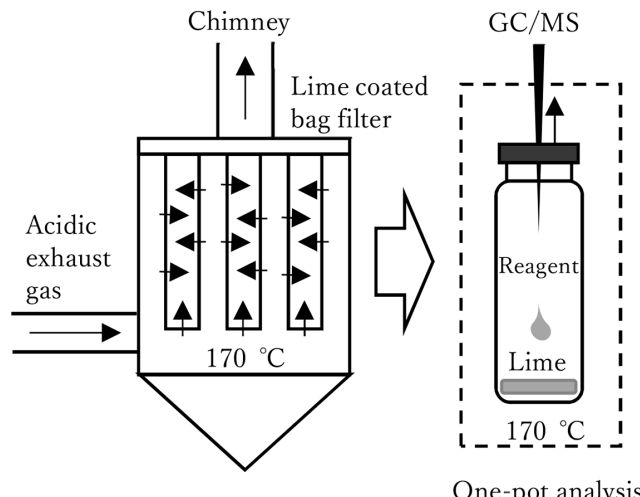

Fig. 1 Schematic diagram of a bag filter and our one-pot analysis

However, unlike 1,4-dioxane formation, the mechanism behind the increased formation of aldehydes after neutralization was unclear. Kosaka et al. noted that formaldehyde is produced by chlorinating amines in the aqueous phase. ${ }^{11}$ Further, amine emulsifiers are used in the production of highly reactive slaked lime used in bag filters of waste incineration facilities. Therefore, active chemical species are exposed to multiple side reactions in the combustion exhaust gas. For example, hypochlorous acid is produced from chlorine gas and is present in substantial amounts in the combustion gas. ${ }^{12,13}$ Moreover, Sekine and Kitahara reported that when ethanol is applied to the surface of plaster in an indoor environment, it reacts with calcium hydroxide to generate acetaldehyde, which undergoes aldol condensation with crotonaldehyde. ${ }^{14}$ However, ethanol and methanol have not been reported to exist in the exhaust gas from waste incineration facilities, since their emissions are not regulated for low toxicity. Therefore, the detection of high concentrations of aldehydes in exhaust gas may be attributed to the reaction between the highly reactive slaked lime and alcohol. Aldehydes are unstable in the gas phase and labeled by the DNPH method or other similar methods, converted to a stable substance, and subjected to high sensitivity analysis. ${ }^{15,16}$ A common analysis method for aldehydes is to collect aldehydes in an air collection tube containing DNPH, derivatize the aldehydes with DNHP, and perform methods such as UV detection high performance liquid chromatography. ${ }^{17-19}$ However, a weakness of DNPH/HPLC analysis is that when sampling air, high relative humidity and low collection temperature are required to maintain the collection efficiency. Such a method is not suitable for the direct analysis of exhaust gas because the exhaust gas cannot be sampled to the collection tube at a high temperature of $170^{\circ} \mathrm{C}$. Therefore, an experimental system, which separates and analyzes aldehydes at the time of generation, is required. In this study, the one-pot evaluation method was developed to be able to characterize slaked lime used on a bag filter. In a headspace vial using a headspace gas chromatography mass spectrometer (HS-GC/MS) (Fig. 1), the reactions and analysis conditions can be changed to easily reproduce to some extent reactions that may occur at the gas/ solid interface in the bag filter, like the generation of aldehyde. And because the generated gas is confined in a sealed container, the sampling of gas will not be incorrect. Further, the generation behavior of aldehydes was investigated. The purpose of this study was to investigate the generation of aldehydes in bag filters coated with highly reactive slaked lime, in waste incinerators.

\section{Experimental}

\section{Reagents and chemicals}

Formaldehyde and acetaldehyde standards were prepared for HS-GC/MS analysis. A formaldehyde standard solution $(1000 \mathrm{mg} / \mathrm{L}$ methanol solution), acquired from Wako Pure Chemical Industries Ltd., was used as the formaldehyde standard. The acetaldehyde standard was prepared by diluting extra-pure acetaldehyde ( $c a .99 .5 \%$ ) manufactured by Wako Pure Chemical Industries Ltd. with infinity pure ethanol (99.5\%). Butanol manufactured by Wako Pure Chemical Industries Ltd. with infinity pure ethanol $(99.5 \%)$. Fluorobenzene was used as an internal standard substance and was prepared by diluting chemical-grade fluorobenzene (Wako Pure Chemical Industries Ltd.) with toluene for air pollutant measurements. The reagent calcium hydroxide, manufactured by Wako Pure Chemical Industries Ltd., was used as the standard slaked lime sample. In addition, two types of highly reactive slaked lime samples for use in bag filters were used. In $\alpha$ samples, $2.0 \mathrm{w} / \mathrm{w} \%$ of diethylene glycol was added as an emulsifier during the manufacturing process, whereas in $\beta$ samples, $2.0 \mathrm{w} / \mathrm{w} \%$ of triethanolamine was added as an emulsifier in the manufacturing process. In addition, calcium carbonate, manufactured by Wako Pure Chemical Industries Ltd., was used as a blank lime sample, since it does not react with alcohol to generate aldehyde. Chemical-grade 2-ethanolamine, diethylamine, and trimethylamine, manufactured by Wako Pure Chemical Industries Ltd., were used as pseudo emulsifiers in the standard slaked lime samples and blank lime samples. Sodium hypochlorite solution (4.0\%) manufactured by Wako Pure Chemical Industries Ltd. was used. All other reagents were of analytical grade.

\section{Sample preparations}

In order to reappear the reaction between lime and alcohol in bag filters to affirm the generation of acetaldehyde and to quantify the formation of it, $0.1 \mathrm{~g}$ of calcium carbonate reagent was weighed as a blank sample in a vial, capped with a special crimp cap using a silicon septum with a polyimide (PI) seal (manufactured by Shimadzu Corporation), and $10 \mu \mathrm{L}$ of a standard solution was added using a syringe pump. Formaldehyde standard solutions were prepared by diluting a formaldehyde methanol solution with methanol to prepare liquid series of 50,100, 200, 500, and $1000 \mu \mathrm{g} / \mathrm{mL}$. Acetaldehyde standard solutions were prepared by diluting an acetaldehyde reagent with ethanol to prepare solutions of 50, 100, 200, 500, $1000,2000,5000$, and $10000 \mu \mathrm{g} / \mathrm{mL}$. Additionally, $5 \mu \mathrm{L}$ of the internal standard was added using a syringe pump. The formaldehyde methanol solution and acetaldehyde ethanol solution were not mixed and calibration curves were prepared separately. Furthermore, samples with only the aldehyde standard solution and internal standard substance (without the blank lime sample) were prepared to evaluate the influence of the matrix.

For experiments conducted to evaluate the type and amount of aldehydes produced by the reaction of alcohols with standard slaked lime, $0.1 \mathrm{~g}$ of the slaked lime sample was weighed and placed in a headspace vial. The vial was capped, which could be used at temperatures up to $300^{\circ} \mathrm{C}$. Thereafter, $1-10 \mu \mathrm{g}$ of methanol or ethanol was added. As an internal standard, $5 \mu \mathrm{g}$ of a $1000 \mu \mathrm{g} / \mathrm{mL}$ fluorobenzene toluene solution was added. A blank lime sample was also prepared. Additionally, a standard slaked lime sample was used as a sample in which the organic matter does not remain on the surface. 
Table 1 Analytical conditions for the HS-GC/MS of formaldehyde, acetaldehyde and other compounds

$\begin{array}{ll}\text { Head space sampler section } & \\ \text { Oven temp. } & 170^{\circ} \mathrm{C} \\ \text { Heat-retention time } & 20 \mathrm{~min} \\ \text { Sample line temperature } & 200^{\circ} \mathrm{C} \\ \text { Transfer line temperature } & 200^{\circ} \mathrm{C} \\ \text { Injection mode } & \mathrm{Loop} \\ \text { Gas pressure for pressurizing vial } & 150 \mathrm{kPa} \\ \text { Sample injection time } & 1.0 \mathrm{~min} \\ \text { GC/MS section } & \\ \text { Temp. program: Initial temp. } & 35^{\circ} \mathrm{C}(5 \mathrm{~min}) \\ \text { Program rate } & 5^{\circ} \mathrm{C} / \mathrm{min} \\ \text { Final temperature } & 290^{\circ} \mathrm{C}(10 \mathrm{~min}) \\ \text { Carrier gas } & \mathrm{He} \\ \text { Splitting rate } & 1: 15 \\ \text { Ion source temperature } & 240^{\circ} \mathrm{C} \\ \text { Ionization method } & \mathrm{EI} \\ \text { Ionization potential } & 70 \mathrm{eV} \\ \text { Interface temperature } & 300^{\circ} \mathrm{C}\end{array}$

In experiments conducted to investigate the type and concentration of aldehydes generated by reacting hydrochloric acid produced in the incinerator with amines remaining in highly reactive lime with a bag filter, $0.1 \mathrm{~g}$ of the slaked lime sample or blank lime sample was weighed, $20 \mu \mathrm{L}$ of concentrated hydrochloric acid was added, and capped with a dedicated crimp cap. Then, $3 \mu \mathrm{L}$ of the amine (2-ethanolamine, diethylamine, or triethylamine) and $5 \mu \mathrm{L}$ of the internal standard substance were added.

In experiments conducted to evaluate the aldehyde formed by the reaction of hydrochloric acid and hypochlorous acid with an actual sample of highly reacted lime, $\alpha$ and $\beta$ of the actual sample in which amines were used as emulsifiers were used. $\alpha$ and $\beta, 0.1 \mathrm{~g}$ of the slaked lime sample was weighed in a $20-\mathrm{mL}$ headspace vial, and $5,10,15$, or $20 \mu \mathrm{L}$ concentrated hydrochloric acid or $4 \%$ sodium chlorite solution was added. After the addition, the vial was immediately capped with a special crimp cap with a PI-sealed silicone septum. Thereafter, $5 \mu \mathrm{L}$ of a fluorobenzene toluene solution was added as an internal standard substance.

\section{Apparatus and analysis conditions}

GCMS-QP2010 Ultra ${ }^{\mathrm{TM}}$ (manufactured by Shimadzu Corporation) was used for gas chromatography mass spectroscopy. HS-20 (manufactured by Shimadzu Corporation) was employed as the head-space sampler. All measurements were performed in the scan mode $(\mathrm{m} / \mathrm{z}, 25-200)$. Additionally, CP-Sil 5 CB for formaldehyde column, manufactured by Agilent $\mathrm{J} \& \mathrm{~W}$ (length $60 \mathrm{~m} \times 0.32 \mathrm{~mm}$ i.d. $\times 8.00 \mu \mathrm{m}$ film thickness), was used for formaldehyde separation. Table 1 lists the details of the HS-GC/MS analysis conditions. The amount of formaldehyde and acetaldehyde generated by the slaked lime samples was calculated per unit weight by employing the calibration curve method and using the relative value of the internal standard substance. Moreover, the analysis sample, which did not use a slaked lime sample, was calculated. The concentration of substances other than aldehydes was evaluated as the relative value of the ion intensity of the main peak. The Wiley MS libraries and National Institute of Standards and Technology (NIST) MS search program 11 were used to identify the compounds detected. Substances exhibiting similarity of $90 \%$ or more were evaluated.

\section{Results and Discussion}

\section{Examination of analysis conditions}

A calibration curve was prepared by using standard solutions with varying concentrations of formaldehyde and acetaldehyde, without the addition of a matrix, such as slaked lime. However, acetaldehyde and methanol could not be separated near the retention time under the current GC/MS analysis conditions. Additionally, formaldehyde was not commercially available, except in a methanol solution. Therefore, separate formaldehyde and acetaldehyde calibration curves were prepared. For the formaldehyde curve, formaldehyde methanol solutions with concentrations ranging from $50-1000 \mu \mathrm{g} / \mathrm{mL}$ were used. The solution was volatilized in a $20-\mathrm{mL}$ vial. The concentration of the gas in the vial was in the range of $25-500 \mathrm{mg} / \mathrm{m}^{3}$. The specific ion intensity of the standard samples at $\mathrm{m} / \mathrm{z}, 29$ was measured using HS-GC/MS and a calibration curve (atmosphere conversion concentration $\left(\mathrm{mg} / \mathrm{m}^{3}\right)$ ) of good linearity was obtained $\left(y=1869.9 x+18767, \quad R^{2}=0.9988\right)$. For the acetaldehyde curve, acetaldehyde ethanol solutions with concentrations ranging from $50-10000 \mu \mathrm{g} / \mathrm{mL}$ were used. Gas state concentrations of aldehydes in the vial ranged from $25-5000 \mathrm{mg} / \mathrm{m}^{3}$. The specific ion intensity of the standard samples at $\mathrm{m} / \mathrm{z} 44$ was measured and a good linearity calibration curve (atmosphere conversion concentration $\left(\mathrm{mg} / \mathrm{m}^{3}\right)$ ) was obtained $\left(y=11966.4 x+1038.7, R^{2}=0.9989\right)$. Further, the influence of matrix coexistence on adsorption was examined. However, as slaked lime reacted with methanol and ethanol (used as a solvents) to generate formaldehyde and acetaldehyde, respectively, it was not possible to create a calibration curve using a slaked lime as a matrix. Therefore, a blank lime sample, which does not react with alcohol and had similar chemical properties, was used instead. A calibration curve was created in the same atmospheric conversion concentration range. A good linearity was obtained between the concentration and specific ionic strength (formaldehyde $m / z 29, y=1452.8 x+8427, R^{2}=$ 0.9996; acetaldehyde $\mathrm{m} / \mathrm{z} \quad 44, \quad y=10255.8 x-18525, \quad R^{2}=$ 0.9976). In addition, the respective relative standard deviation was 3.6 and $3.9 \%$ when $50 \mu \mathrm{g} / \mathrm{mL}$ formaldehyde and acetaldehyde standard samples were measured five times. Thus, the limit of quantification was determined to be $25 \mathrm{mg} / \mathrm{m}^{3}$. When blank lime samples were added, they were reduced to 78 and $86 \%$ for formaldehyde and acetaldehyde, respectively, compared to no matrix addition.

Further, the influence of the matrix on the decomposition and adsorption of aldehydes was assessed. The heat retention time at the headspace sampler was set for 5, 10, 20, and $30 \mathrm{~min}$. The lowest and highest relative intensity value of acetaldehyde was obtained after heating for 5 and $20 \mathrm{~min}$. When the heating time is set at 5 and $20 \mathrm{~min}$, the relative strength of acetaldehyde added with the blank lime is 109 and $123 \%$ of the samples without matrix, respectively. Thus, the influence of the adsorption of aldehydes on the matrix was significant. It was assumed that the effects of thermal decomposition were small. The heat retention temperature was set as $170^{\circ} \mathrm{C}$, because the temperature of the gas passing through the bag filter at the incineration treatment facility was $170^{\circ} \mathrm{C} .{ }^{20}$

\section{Aldehydes generation from slaked lime following alcohol addition}

The generation of aldehydes was investigated when alcohols (methanol, ethanol, and butanol) reacted at $170^{\circ} \mathrm{C}$ with standard slaked lime samples. Figures 2(a) - 2(c), respectively, depict the chromatograms of methanol, ethanol, and butanol addition. 


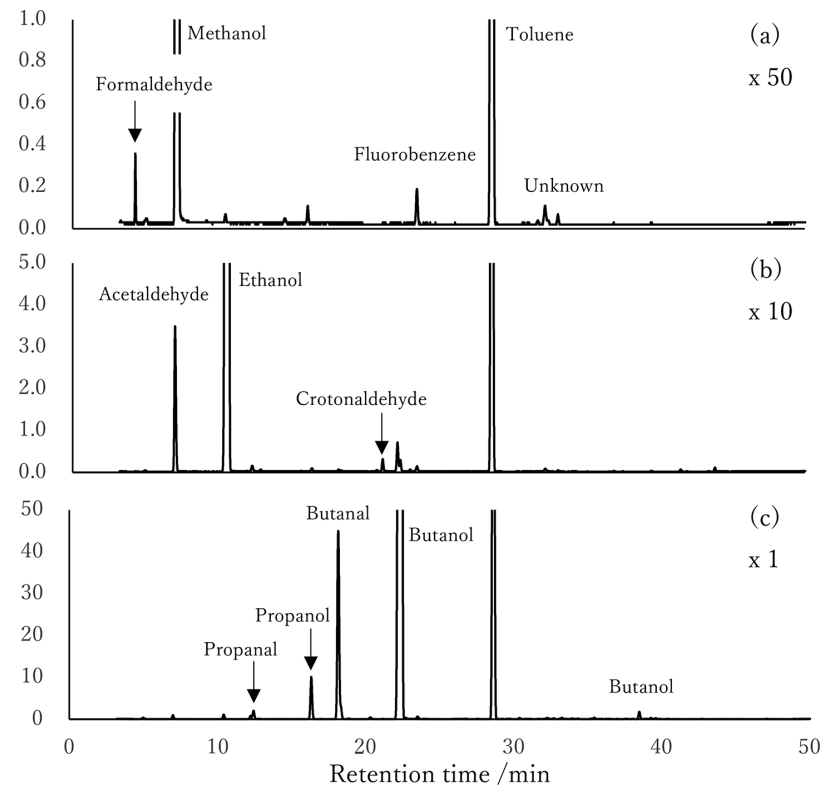

Fig. 2 Total ion chromatograms (TICs) of products from reactions of standard $\mathrm{Ca}(\mathrm{OH})_{2}$ and an alcohol: (a) methanol, (b) ethanol, and (c) butanol.

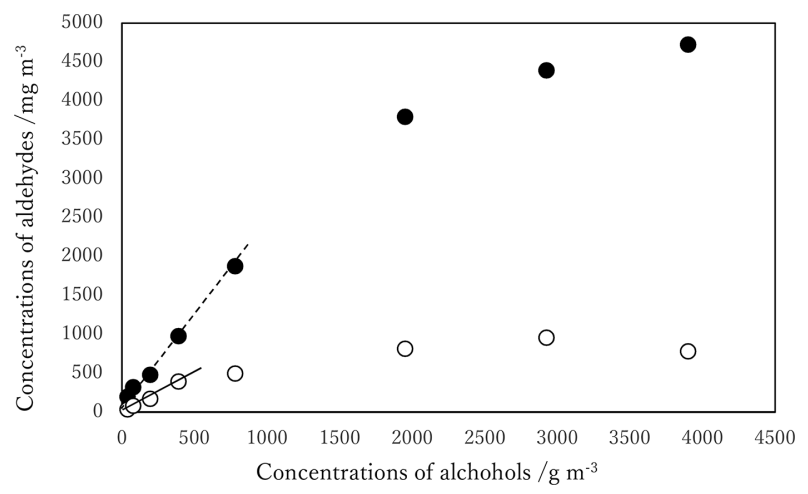

Fig. 3 Formation of aldehydes from alcohols on the surface of $\mathrm{Ca}(\mathrm{OH})_{2}$ powder: $(\mathrm{O})$ formaldehyde and $(\bullet)$ acetaldehyde.

Formaldehyde was generated from methanol, acetaldehyde was generated from ethanol, and butanal was generated from butanol. When ethanol was added to slaked lime, crotonaldehyde was formed by aldol condensation of acetaldehyde; the result was consistent with Sekine and Kitahara. ${ }^{14}$ The amount of aldehyde generated when $1-100 \mu \mathrm{L}$ of the alcohol was added $\left(39-3900 \mathrm{~g} / \mathrm{m}^{3}\right.$ : atmospheric conversion concentration) and the rate of conversion of alcohols to aldehydes are shown in Fig. 3. An increase in the concentration of formaldehyde was also confirmed with methanol and ethanol at concentrations of $790 \mathrm{~g} / \mathrm{m}^{3}$ or more. The rate of conversion to aldehydes was calculated using a relationship between alcohols and aldehydes in the range of $0-316 \mathrm{~g} / \mathrm{m}^{3}$ as a line passing through the origin; it was $0.097 \%$ for formaldehyde and $0.260 \%$ for acetaldehyde. The conversion rate was calculated as:

$$
\text { Conversion rate }(\%)=\frac{C_{\text {aldehyde }} \times V_{\text {vial }} \times M_{\text {alcohol }}}{\rho_{\text {alcohol }} \times V_{\text {alcohol }}} \times 100,
$$

where $C_{\text {aldehyde }}$ represents the concentration of formaldehyde and

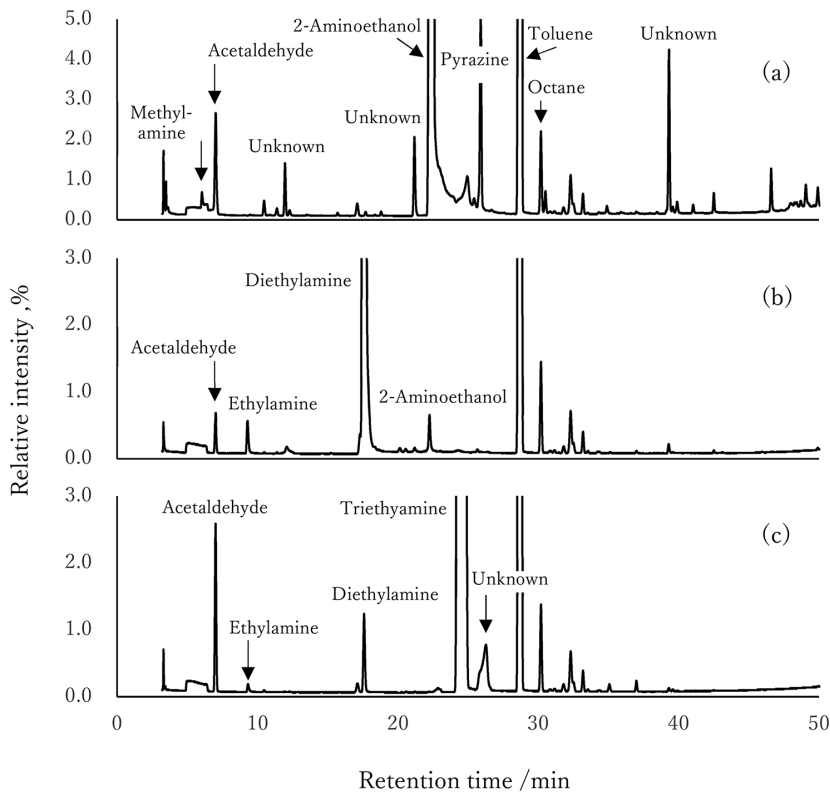

Fig. 4 Total ion chromatograms (TICs) of products from reactions of $\mathrm{HCl}$, standard $\mathrm{Ca}(\mathrm{OH})_{2}$, and an amine: (a) 2-aminoethanol, (b) diethylamine, and (c) trimethylamine.

acetaldehyde in air in vial, $V_{\text {alcohol }}$ represents the volume, $M_{\text {alcohol }}$ is the molar mass, $\rho_{\text {alcohol }}$ is the density of the added alcohol, and $V_{\text {vial }}$ is the HS vial volume, which was $20 \mathrm{~mL}$.

Oguchi $^{3}$ reported that formaldehyde and acetaldehyde were detected in concentration ranges of $0-290 \mu \mathrm{g} / \mathrm{m}^{3}\left(0 \mu \mathrm{g} / \mathrm{m}^{3}\right.$ means not detected) and $2-1400 \mu \mathrm{g} / \mathrm{m}^{3}$, respectively, in the final exhaust gas of waste incineration treatment facilities. It is assumed that formaldehyde and acetaldehyde were all produced by the reaction of slaked lime and alcohol, which Oguchi measured in the final exhaust gas. Substituting the concentrations of formaldehyde and acetaldehyde in the exhaust gas into formula (1) can be used to calculate the concentration of alcohol used in the reaction. Then, the concentrations of methanol and ethanol were calculated as $0-299$ and $0.8-538 \mu \mathrm{g} / \mathrm{m}^{3}$, respectively. In addition, since the thermodynamic stability of butanal is higher than formaldehyde and acetaldehyde, it is difficult to be oxidized to carboxylic acid, and its abundance as aldehyde is higher than those of formaldehyde and acetaldehyde. As a result, the production of butanal was 12 times (at the ionic strength of $m / z$ 44) higher than acetaldehyde.

\section{Aldehydes generation from slaked lime following addition of amines}

Some amines used as emulsifying agents during slaked lime production. The TIC of the product generated when amines (2-aminoethanol, diethylamine, and trimethylamine) on the surface of slaked lime coexisted with acid gas (atmospheric conversion concentration of $\mathrm{HCl}: 110 \mathrm{~g} / \mathrm{m}^{3}$ ) is shown in Figs. 4(a) - 4(c). Acetaldehyde was produced from all of the amines, but formaldehyde was not generated from all them. Some substances detected among the decomposition products of amines and reagents were considered to be impurities. When 2-aminoethanol was added, methylamine and pyrazine were detected, and the largest quantity of substances among the three amines was detected. When diethylamine was added, ethylamine and 2-aminoethanol were detected. When triethylamine was added, only ethylamine and diethylamine, which were present as impurities, were detected. The amount of acetaldehyde 


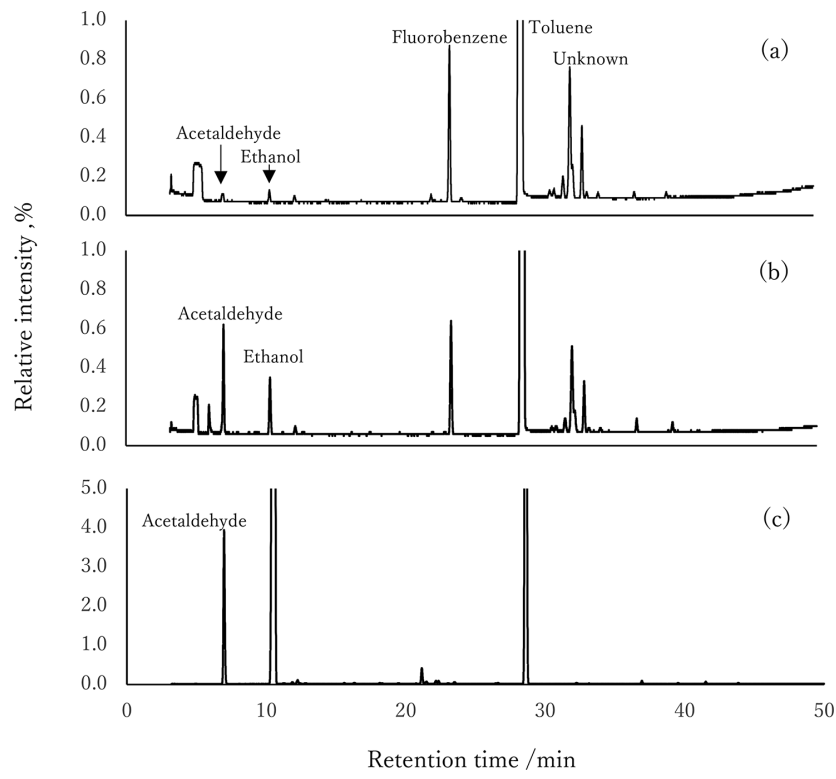

Fig. 5 Total ion chromatograms (TICs) of slaked lime reaction products: (a) slaked lime $\alpha$ with $10 \mu \mathrm{L}$ of $\mathrm{HCl}$, (b) slaked lime $\beta$ with $10 \mu \mathrm{L}$ of $\mathrm{HCl}$, and (c) slaked lime $\beta$ with $10 \mu \mathrm{L}$ of ethanol.

generated from 2-aminoethanol, diethylamine, and triethylamine was 500,157 , and $3681 \mathrm{mg} / \mathrm{m}^{3}$, respectively, assuming that the amines added $(30 \mu \mathrm{g} / \mathrm{g})$ were on the surface of the lime, under similar reaction conditions. These results indicated that triethylamine generated the highest amount of acetaldehyde. However, as the decomposition of amines by chlorination in water also generates formaldehyde, the simulation conditions in this study could have inhibited the formation of formaldehyde or contributed to the immediate decomposition of the formed formaldehyde.

Formation of aldehydes from highly reactive slaked lime (product) Figures 5(a)-5(c) represent chromatograms obtained by adding $10 \mu \mathrm{L}$ of concentrated hydrochloric acid to individual samples of slaked lime $\alpha$ and $\beta$, and a chromatogram obtained by adding $10 \mu \mathrm{L}$ ethanol to slaked lime $\beta$. Acetaldehyde was produced in trace amounts (atmosphere conversion concentration: $11 \mathrm{mg} / \mathrm{m}^{3}$ ) from the slaked lime $\alpha$. However, $95 \mathrm{mg} / \mathrm{m}^{3}$ of acetaldehyde was produced from slaked lime $\beta$, which was considered to be mainly derived from amines. Further, in slaked lime $\beta$, the amount of acetaldehyde produced tended to increase with an increase in the amount of concentrated hydrochloric acid and hypochlorous acid. The maximum concentration of acetaldehyde reached $121 \mathrm{mg} / \mathrm{m}^{3}$, under the condition of the addition of $20 \mu \mathrm{L}$ concentrated hydrochloric acid. In slaked lime $\alpha$, no significant difference was found in the concentration of acetaldehyde when the amount of concentrated hydrochloric acid was changed. However, formaldehyde formation due to amines during chlorination in the water-treatment process, as reported by Kosaka et al., ${ }^{11}$ could not be confirmed. This suggests that the mechanism of aldehyde formation differs between the water and gas phases or gas-solid interface. The amount of acetaldehyde produced changed when the amount of hypochlorous acid and hydrochloric acid (unit: $\mathrm{mol} / \mathrm{m}^{3}$ ) added to slaked lime $\beta$ was increased, and is shown in Fig. 6 . The aqueous solution of sodium hypochlorite and amount of concentrated hydrochloric acid added are expressed in atmospheric equivalent (unit: $\mathrm{mol} / \mathrm{m}^{3}$ ). Acetaldehyde increased

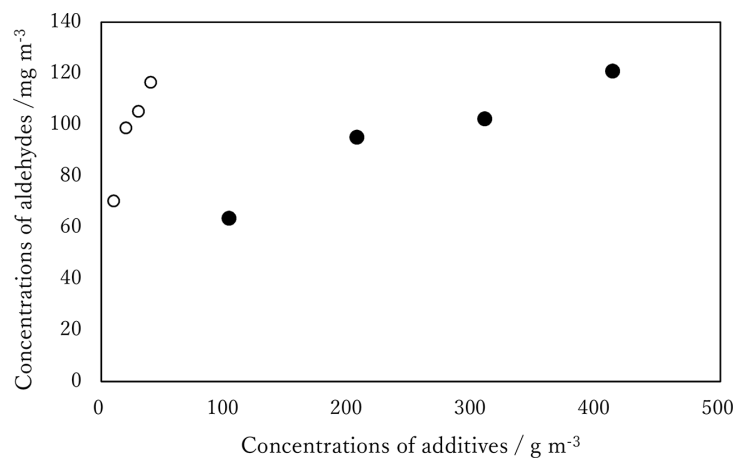

Fig. 6 Changes in the acetaldehyde concentration when concentrated hydrochloric acid $(\bullet)$ and hypochlorous acid $(\bigcirc)$ were added to slaked lime $\beta$.

rapidly with the addition of $5 \mu \mathrm{L}$ ( $\mathrm{HClO}: 0.19 \mathrm{~mol} / \mathrm{m}^{3}, \mathrm{HCl}$ : $3.0 \mathrm{~mol} / \mathrm{m}^{3}$ ), and thereafter the rate of the increase decreased. The initial formation of acetaldehyde was evaluated. Sodium hypochlorite was added to slaked lime $\beta$ per unit weight (g) as a source of hypochlorous acid gas and concentrated hydrochloric acid was added as hydrochloric acid gas. The amount of acetaldehyde formed per $\mathrm{mol} / \mathrm{m}^{3}$ of acids was calculated as:

$$
C_{1}=\frac{C_{\text {aldehyde }} \times M_{\text {acid }}}{\rho_{\text {acid }} \times V_{\text {acid }} \times C_{\text {acid }}},
$$

where $C_{1}$ is the concentration of aldehyde formed after the addition of $1 \mathrm{~mol}$ acid; $C_{\text {aldehyde }}$ is the atmospheric equivalent concentration of formaldehyde or acetaldehyde formed from amine after hydrochloric acid and hypochlorous acid addition; $\rho_{\text {acid }}, V_{\text {acid }}$, and $M_{\text {acid }}$, respectively, represent the density, added volume, and molar mass of hydrochloric acid and hypochlorous acid; and $C_{\text {acid }}$ is the mass percent concentration of the added acid.

The concentration of acetaldehyde formed per mol amount of alcohol added ( $1 \mathrm{~mol})$ was calculated as

$$
C_{2}=\frac{C_{\text {aldehyde }} \times M_{\text {alcohol }}}{\rho_{\text {alcohol }} \times V_{\text {alcohol }}},
$$

where $C_{2}$ is the concentration of aldehyde formed after the addition of $1 \mathrm{~mol}$ alcohol; $C_{\text {aldehyde }}$ is the air-equivalent concentration of formaldehyde or acetaldehyde produced from methanol and ethanol; and $\rho_{\text {alcohol }}, V_{\text {alcohol }}, M_{\text {alcohol }}$, respectively represent the densities of methanol and ethanol, added volume, and molar mass.

The amount of acetaldehyde formed from slaked lime $\beta$ by hypochlorous acid and hydrochloric acid was calculated according to Eq. (2) as $371 \mathrm{mg} / \mathrm{m}^{3} \cdot \mathrm{mol}(\mathrm{HClO})$ and $34.4 \mathrm{mg} / \mathrm{m}^{3} \cdot \mathrm{mol}$ ( $\mathrm{HCl})$ when acids added $10 \mu \mathrm{L}$, respectively. Thus, the study found that hypochlorous acid species were more effective in producing acetaldehyde from amines. The concentration of aldehydes produced was $16.8 \mathrm{mg} / \mathrm{m}^{3} \cdot \mathrm{mol}(\mathrm{HCl})$, which is nearly one-third (Fig. 5) of $50.5 \mathrm{mg} / \mathrm{m}^{3} \cdot \mathrm{mol}$ (ethanol), produced by adding $10 \mu \mathrm{L}$ of alcohol (calculated according to Eq. (3)). Although the amount of aldehyde generated by the addition of acid was not a small value, there are few examples where amines are used as an emulsifier used in the production of highly reactive slaked lime. For this reason, it is assumed that the formation of aldehydes by alcohol is important.

In this study, the atmospheric concentration of concentrated 
hydrochloric acid (to which $10 \mu \mathrm{L}$ of alcohol was added) was $200 \mathrm{~g} / \mathrm{m}^{3}$, and the actual hydrogen chloride gas concentration in the incinerator was about $0.5-2 \mathrm{~g} / \mathrm{m}^{3}$; thus, the experiment was performed in the high-concentration region. Therefore, low-concentration conditions were tried using diluted acid and alcohol. However, since the side reaction caused by the increase in the solvent and water greatly affected acetaldehyde formation, in this study, highly reactive slaked lime was evaluated by experiments conducted under high-concentration conditions.

\section{Conclusions}

Methanol and ethanol are chemical substances that can be released into the environment at low concentrations in the final exhaust gas of waste incineration facilities. This study shows that alcohols can be easily converted to aldehydes, which are harmful. Moreover, the conversion rate of alcohols to aldehydes obtained in this study clarifies the behavior of aldehydes. But the conversion rate calculated in this study cannot be used directly to determine the amount of aldehydes generated in the final exhaust gas from waste incineration facilities as the bag filter environment reproduced in this study differs from the actual production conditions. Further, the contact time, flow rate, and catalytic effect are different. However, the one-pot evaluation method using HS-GCMS proposed in this study can be used for the initial evaluation of aldehydes unexpectedly generated in incineration facilities in the future. And besides the method developed in this study, there is no method that can easily trace the reaction in the bag filter of the waste incineration treatment facility.

\section{References}

1. M. Hiraoka, Waste Manage. Res., 1997, 8, 265.

2. S. Kumagai, S. Koda, and H. Oda, Ind. Health., 2003, 41 , 167.

3. M. Oguchi, "Estimation of Substance Flows and
Environmental Emissions of Chemicals Associated with Waste Incineration", 2017, Final Report of Environment Research and Technology Development Fund, 3K153003, Tokyo, Japan.

4. M. Mehl, A. Marongiu, T. Faravelli, G. Bozzano, M. Dente, and E. Ranzi, J. Anal. Appl. Pyrolysis, 2004, 72, 253.

5. I. Aracil, R. Font, and J. A. Conesa, J. Anal. Appl. Pyrolysis, 2005, 74, 465 .

6. Y. Miyake, M. Tokumura, Q. Wang, T. Amagai, Y. Horii, and K. Kannan, Environ. Sci. Technol., 2017, 51, 14100.

7. WHO (World Health Organisation), "Air Quality Guidelines for Europe", WHO European Series No. 23, 1987, Copenhagen, Denmark.

8. CEPA (California Environmental Protection Agency), "Acetaldehyde as a Toxic Air Contaminant. Part A: Exposure; Part B: Health Assessment", 1993, Air Resources Board, Stationary Source Division, Sacramento, CA, USA.

9. Y. Fuse, H. Mizuguchi, Y. Yotsu, H. Karatani, and E. Yamada, J. Environ. Saf., 2017, 8, 113.

10. X. Chu and Y. Fuse, Bunseki Kagaku, 2019, 68, 339.

11. K. Kosaka, M. Asami, T. Nakai, K. Ohkubo, S. Echigo, and M. Akiba, Sci. Total Environ., 2014, 488, 325.

12. N. Hirayama, K. Hishida, S. Konon, and T. Orira, Bull. JSME, 1968, 11, 902.

13. E. Fujimori, S. Iwata, K. Minamoto, K. Lee, A. Itoh, K. Chiba, and H. Haraguchi, Anal. Sci., 2004, 20, 189.

14. Y. Sekine and T. Kitahara, Jpn. J. Clin. Ecol., 2013, 22, 120.

15. F. Lipari and S. J. Swarm, Environ. Sci. Technol., 1985, 19, 70

16. R. L. Tanner and Z. Meng, Environ. Sci. Technol., 1984, 18 , 723.

17. A. Yasuhara, J. Environ. Chem., 1991, 1, 253.

18. D. Grosjean, Environ. Sci. Technol., 1982, 16, 254.

19. R. L. Tanner and Z. Meng, Environ. Sci. Technol., 1984, 18, 723.

20. T. Fujii, T. Murakawa, N. Maeda, M. Kondo, K. Nagai, T. Hana, and K. Ota, Chemosphere, 1994, 29, 2067. 